\title{
BMJ Open Associations between e-health questionnaire responses, health checks and graduation: Finnish register-based study of 2011-2012 university entrants
}

\author{
Noora Seilo (D) , ${ }^{1}$ Susanna Paldanius, ${ }^{1}$ Reija Autio, ${ }^{2}$ Kristina Kunttu, ${ }^{3}$ \\ Minna Kaila (1) ${ }^{4}$
}

To cite: Seilo N, Paldanius S, Autio R, et al. Associations between e-health questionnaire responses, health checks and graduation: Finnish registerbased study of 2011-2012 university entrants. BMJ Open 2020;10:e041551. doi:10.1136/ bmjopen-2020-041551

- Prepublication history and supplemental material for this paper are available online. To view these files, please visit the journal online (http://dx.doi. org/10.1136/bmjopen-2020041551).

Received 11 June 2020 Revised 19 November 2020 Accepted 24 November 2020

A) Check for updates

(C) Author(s) (or their employer(s)) 2020. Re-use permitted under CC BY-NC. No commercial re-use. See rights and permissions. Published by BMJ.

${ }^{1}$ Faculty of Medicine and Health Technology, Tampere University, Tampere, Finland

${ }^{2}$ Faculty of Social Sciences, Tampere University, Tampere, Finland

${ }^{3}$ Finnish Student Health Service, Helsinki, Finland

${ }^{4}$ Public Health Medicine,

University of Helsinki, Helsinki, Finland

Correspondence to

Dr Noora Seilo;

noora.seilo@tuni.fi

\section{ABSTRACT}

Objective To evaluate the association between health and study-related factors measured by an Electronic Health Questionnaire (eHQ), participation in a health examination process and graduation in a university student population. Design Nationwide, retrospective, register-based cohort study with a 6-year follow-up.

Setting Student health care in Finland. Finnish Student Health Service (FSHS) provides statutory student health services to university students in Finland. The health examination process of FSHS includes the $\mathrm{eHQ}$ provided annually to university entrants and a subsequent health check when necessary based on students' eHQ response. Participants A national cohort of university entrants from the 2011-2012 academic year $(n=14329, n$ (female) $=8075, \mathrm{n}$ (male) $=6254$ ).

Outcome measures The primary outcome measure was graduation, measured based on whether a student had completed a bachelor's, licentiate or master's degree during the 6-year follow-up.

Results Some $72 \%$ of the women and $60 \%$ of the men had graduated during the follow-up. The predictors in the $\mathrm{eHQ}$ associated with non-graduation differed by sex. Among the women's low enthusiasm about studies (OR 2.6, $95 \% \mathrm{Cl} 1.9$ to 3.6), low engagement with studies (OR 2.5, 95\% Cl 1.8 to 3.4) and daily smoking (OR 1.9, $95 \% \mathrm{Cl} 1.4$ to 2.6 ) were the strongest predictors to non-graduation. Among the men, low engagement with studies (OR 3.7, 95\% Cl 2.5 to 5.5) and obesity (body mass index $\geq 35)(0 \mathrm{R} 4.0,95 \% \mathrm{Cl} 1.9$ to 8.8) were the strongest predictors to non-graduation. Not attending the health check when referred was associated with non-graduation in both sexes: the OR for not graduating was $1.6(95 \% \mathrm{Cl}$ 1.3 to 1.9$)$ in women and $1.3(95 \% \mathrm{Cl} 1.0$ to 1.6$)$ in men. Conclusions Engagement and enthusiasm about studying in the first year are important predictors of graduation and therefore a potential intervention target. Health promotion initiatives conducted early in the studies may have a positive effect on students' academic achievement.

\section{INTRODUCTION}

A reasonable amount of evidence on the association between health-related factors and academic achievement is available; however, the evidence is contradictory. A
Strengths and limitations of this study

- This was the first study to investigate the association between health checks and graduation.

- The major strength of the study was the study population, which consisted of the whole cohort of university entrants in Finland from the 2011-2012 academic year.

- The main limitations of the study were the relatively low response rate to the Electronic Health Questionnaire (55\%), a heavy reliance on the nurses' professional competence in interpreting the questionnaire and the use of self-reported data.

- The $\mathrm{eHQ}$ was developed for practical purposes, and therefore all questions were not validated.

reciprocal relationship between health, health behaviour and academic achievement has been suggested. ${ }^{1}$ Poor health can affect academic performance, whereas poor academic performance can cause health issues. A deeper understanding how the wellbeing of students is associated with academic achievement is needed to develop student healthcare services in order to detect risk factors for study ability as early as possible. Study ability is student's work ability, the concept of which is presented elsewhere. ${ }^{2}$

In Finland, unlike in some other countries, the health and health habits of the university students are better compared with their peers either studying at universities of applied sciences or working. ${ }^{3-5}$ In numerous countries, Finland included, there is widespread concern about the mental health of university students. ${ }^{36-8}$ Some $34 \%$ of Finnish higher education students have reported moderate or poor psychological well-being. ${ }^{3}$ Mental health issues are considered to be one of the biggest health-related threats for academic achievement. $^{9-15}$ 
The prevalence of sleeping problems is high in the university student population. ${ }^{316}$ Sleep quality and sleep habits have been indicated to be associated with academic performance, ${ }^{91718}$ though in some studies no association has been detected. ${ }^{119}$ In addition, evidence of the association between academic achievement and physical activity in the university student population is contradictory. ${ }^{9} 1720$ A meta-analysis including also several studies with college students revealed a negative correlation between body mass index (BMI) and academic achievement. ${ }^{21}$

Finnish Student Health Service (FSHS) provides student healthcare services, including medical care, to all bachelor's and master's degree students and medical licentiate students (approximately 125000 ) in universities in Finland. The basis of preventive work in FSHS is a statutory health examination process that was designed to identify and support students at risk of decreased study ability. ${ }^{22} 23$ The process includes an Electronic Health Questionnaire (eHQ) provided to all university entrants and a subsequent health check when necessary based on the students' eHQ responses. The eHQ consists of several questions about health, social relations and studying, and it has been shown to facilitate the identification of students' health problems. ${ }^{24}$ The health check is a general health check conducted by a public health nurse. Participation in the health examination process is voluntary for students.

To our knowledge, no studies have been conducted about the association between health checks and academic achievement. Health and study-related factors associated with academic achievement have mostly been studied separately and more in school-aged children than in university students. ${ }^{125-29}$

We aimed to use the data from FSHS health examination process to explore the associations between student's health, social relations and approach to studies at entry, and their graduation.

Specifically, the objectives of the study were

1. How are university entrants' responses to the eHQ questions associated with graduation during a 6-year follow-up?

2. How is participating in the FSHS health examination process associated with graduation during a 6-year follow-up?

\section{METHODS}

This was a nationwide register-based cohort study with a 6-year follow-up, the design and methodology of which have been described previously. ${ }^{2}$ We used the Strengthening the Reporting of Observational Studies in Epidemiology cohort checklist when writing our report. ${ }^{30}$ The study was a real-life study on an ongoing FSHS health examination process. It used the data that the process produced about the health of university entrants, and these were analysed in relation to the students' graduation. The population was the whole cohort of university entrants from the 2011 to 2012 academic year in Finland

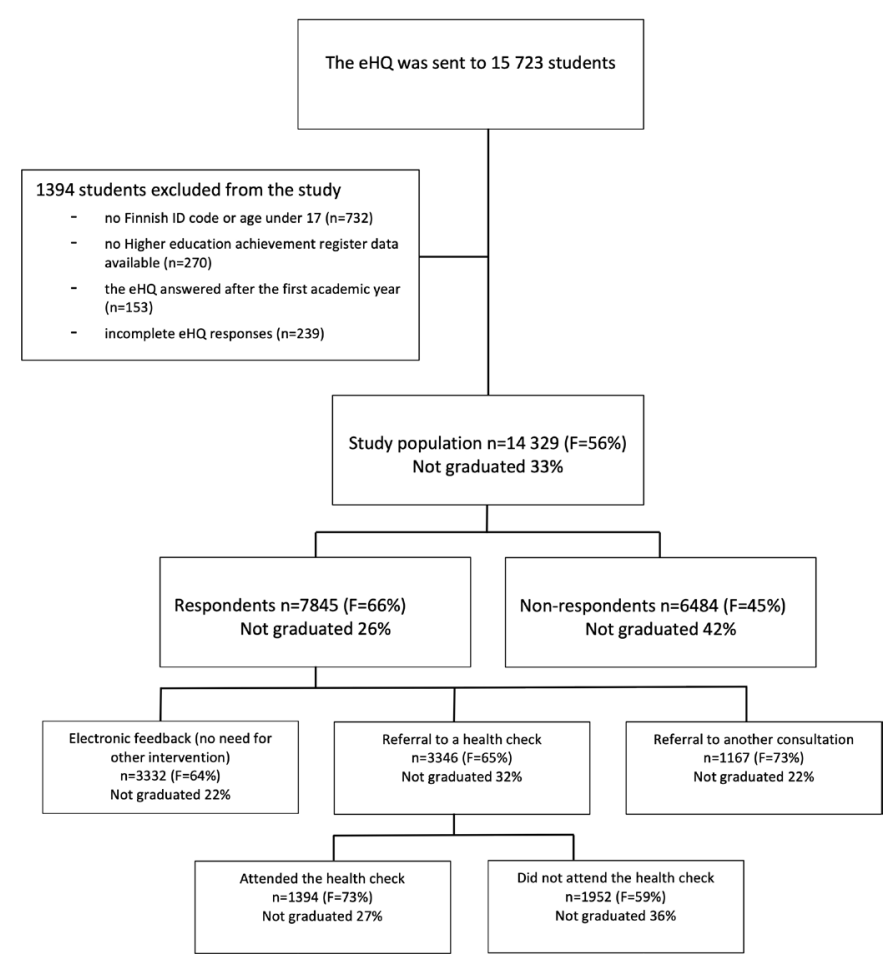

Figure 1 Participation in the health examination process, the exclusion criteria of the study and the proportions of the non-graduated students $(n=4786)$ in each step of the health examination process. eHQ, Electronic Health Questionnaire; FSHS, Finnish Student Health Service; ID, identification.

$(\mathrm{n}=15723)$. The final study population in the analyses consisted of 14329 students after exclusions (figure 1). In Finland, university admission means that the admitted students can continue their studies directly to the master's degree (graduate) after gaining the bachelor's degree (undergraduate). Accordingly, the word entrants in this study indicate students admitted to the undergraduate studies.

\section{Electronic health questionnaire}

The eHQ comprised 26 questions about health, social relations and studying (online supplemental file 1). The responses were considered and handled by FSHS public health nurses. Based on the eHQ response, the nurse suggested to the student one of the following interventions: (1) referral to a health check conducted by a public health nurse; (2) referral to an appointment other than a health check, for example, physiotherapy; or (3) in case there was no need for other interventions, an electronic message to the student to support a healthy lifestyle.

Ten of the eHQ questions had a response scale from -10 to +10 . Respondents were guided to interpret the scale so that positive numbers suggested a favourable situation, and zero $(0)$ suggested a neutral situation. Negative numbers suggested a problematic situation. The distributions of the responses were highly skewed to the high positive end of the scale. We wanted to examine whether also low positive values indicated a problematic situation. The responses were therefore categorised into three 
categories for statistical analysis as high (8-10), medium $(0-7)$ and low $(-10$ to -1$)$.

Drug use of was assessed by asking 'Have you experimented with or used any drugs or taken alcohol and medication at the same time in order to get intoxicated?'. The response alternatives were 'never'; 'yes, 1-4 times'; and 'yes, 5 times or more often'. For the statistical analysis, the latter two responses were combined into one 'yes' category.

Alcohol use was assessed by asking 'Do you use alcohol?' . Subsequent to the response 'yes', the 10-item Alcohol Use Disorders Identification Test (AUDIT) was presented. ${ }^{31}$ AUDIT points were calculated and categorised into four categories according to the WHO classification: $<8$ low risk, $8-15$ medium risk, $16-20$ high risk and $>20$ possible alcohol dependence. ${ }^{32}$

Age was categorised as in the Eurostudent study and in the Finnish University Students' Health Survey as follows: 17-21 years, 22-24 years, 25-29 years and 30 years or older. ${ }^{333}$ Students reported their height and weight in the eHQ. BMI was calculated and categorised following the WHO categorisation: < 18.5 (underweight), 18.5-24.99 (normal weight), 25.0-29.99 (overweight), 30.0-34.99 (obese, Class I), $\geq 35$ (obese, classes II and III). ${ }^{34}$

The eHQ data included register-based information about the faculty of the students. For statistical analyses, the faculties were categorised to form the variable 'field of study'. The categorisation was based on the classification in the Finnish University Students' Health Survey and is in accordance with the field of studies listed by the Ministry of Education and Culture. ${ }^{3}$ Some faculties could not be categorised due to representing two categories and were therefore categorised as 'other'.

\section{Academic achievement}

Academic achievement was measured on the basis of whether a student had completed a bachelor's, licentiate or master's degree within six academic years. Completing a degree was defined as 'graduated' and was used as a dependent variable in this study. Medical, dental and veterinary medicine students achieve a licentiate or master's degree not preceded by a bachelor's degree, while not all bachelors continue to a master's degree.

In Finland, the median time to complete a degree was 3.8 years for a bachelor's degree and 5.9 years for a master's degree (including a bachelor's degree) in 2017 when the follow-up time of this study ended. ${ }^{35}$

\section{Data sources}

The eHQ data were obtained from the eHQ register of FSHS for the 2011-2012 academic year. The information about students' attendance at the health check was collected from FSHS medical records. The data about the number of terms the students were registered as present at the university, and the graduation data were obtained from the Higher education achievement register of the National data warehouse for higher education from the beginning of the 2011-2012 academic year to the end of the 2016-2017 academic year.

The data were linked by using Finnish personal identity codes ${ }^{36}$ In 1964, Finland introduced a personal identification code system, and since then, practically all administrative registers have included this unique identification code, which enables data linkage between the registers and individual-level analyses. ${ }^{37}$ The information about the sex of the students was based on the personal identity codes.

\section{Statistical analysis}

To describe the data, the frequencies and percentages of each variable were calculated. $\chi^{2}$ tests were employed to detect associations between the categorical variables. In cases with continuous non-normally distributed data, the Mann-Whitney $\mathrm{U}$ test was used to detect the differences between groups. A $p$ value of $<0.01$ was considered to be statistically significant.

The data were analysed with a binary logistic regression model to detect the variables in the eHQ and interventions based on the eHQ that were statistically significantly associated with non-graduation. In the logistic regression models, the ORs of the categorical variables were compared against the reference category of each variable, with the exception that the field of study was compared against the mean of all study fields. First, univariate models were created for each predictor separately. Further, as many of the students may have had several risk factors, the model was adjusted by using multivariable logistic regression with which we computed the adjusted ORs that have been adjusted for other covariates, including possible confounders.

The analyses were performed for men and women separately due to the different pattern of significant predictors for each sex. Adjusted models were created for both sexes, and the variables having $\mathrm{p}<0.01$ in either one of the sexes were included in the final adjusted models. Unadjusted and adjusted ORs with 95\% confidence intervals (CI) were computed. All statistical analyses were carried out using IBM SPSS Statistics for Windows V.26 and R V.3.6.1 (The R Foundation), with package ggplot2. ${ }^{38} 39$

\section{Patient or public involvement}

The study was register-based and therefore, patients or members of the public were not involved in the study.

\section{RESULTS}

The demographics of the study population $(n=14329)$ are presented in table 1.

Overall, $67 \%$ of the students $(n=9543)$ had graduated in the 6-year follow-up (table 1 and figure 1). Some $72 \%$ of the women and $60 \%$ of the men had graduated. Of those graduating, $49 \%$ of the women and $52 \%$ of the men had completed only a bachelor's degree. The proportion of the non-graduates over the 6-year follow-up was highest 
Table 1 Demographics of the study population $(n=14329)$ by graduation during the 6 -year follow-up and by sex

\begin{tabular}{|c|c|c|c|c|c|}
\hline & \multicolumn{2}{|c|}{ Total $(n=14329)$} & \multicolumn{2}{|c|}{ Not graduated $(n=4786)$} & \multirow[b]{3}{*}{$P$ value } \\
\hline & $\begin{array}{l}\begin{array}{l}\text { Female } \\
(n=8075)\end{array} \\
\end{array}$ & $\begin{array}{l}\text { Male } \\
(n=6254)\end{array}$ & $\begin{array}{l}\text { Female } \\
(\mathrm{n}=2275)\end{array}$ & $\begin{array}{l}\text { Male } \\
(n=2511)\end{array}$ & \\
\hline & $\%$ & $\%$ & $\%$ & $\%$ & \\
\hline Age (years) & & & & & $<0.001$ \\
\hline $17-21$ & 65 & 66 & 27 & 39 & \\
\hline $22-24$ & 13 & 14 & 28 & 40 & \\
\hline $25-29$ & 11 & 11 & 33 & 42 & \\
\hline$\geq 30$ & 12 & 9 & 31 & 47 & \\
\hline Field of study & & & & & $<0.001$ \\
\hline Humanities, theology, philosophy & 21 & 9 & 28 & 35 & \\
\hline $\begin{array}{l}\text { Sports science, educational sciences, health sciences, } \\
\text { psychology }\end{array}$ & 16 & 8 & 18 & 37 & \\
\hline Technology and engineering & 14 & 28 & 30 & 41 & \\
\hline Natural sciences, agriculture and forestry, and pharmacy & 14 & 19 & 41 & 53 & \\
\hline Social sciences & 12 & 9 & 21 & 32 & \\
\hline Business and economics & 7 & 14 & 24 & 31 & \\
\hline Arts & 5 & 3 & 30 & 35 & \\
\hline Medicine & 4 & 3 & 50 & 53 & \\
\hline Law & 3 & 2 & 18 & 28 & \\
\hline Other & 4 & 5 & 30 & 43 & \\
\hline
\end{tabular}

The proportion of non-graduates was calculated from the total number of students. The field of study is presented in descending order by the total number of female students. Differences between graduates and non-graduates were tested with the $\chi^{2}$ test.

among medical students and lowest among law students (table 1).

Of the study population, $55 \% \quad(\mathrm{n}=7845)$ responded to the eHQ. Of the respondents, $43 \%$ were referred to a health check and $42 \%$ of those referred attended the health check (figure 1). Of the female eHQ respondents, $23 \%$ and of the non-respondents $37 \%$ had not graduated during the 6-year follow-up. The difference between female respondents and non-respondents was statistically significant $(p<0.001)$. Correspondingly, among men, $32 \%$ of the respondents and $46 \%$ of the non-respondents had not graduated $(\mathrm{p}<0.001)$. Among women, $25 \%$ of the health check attendees and 32\% of the non-attendees had not graduated $(\mathrm{p}<0.001)$. The proportions for men were $32 \%$ and $41 \%(p<0.001)$, respectively.

The eHQ respondents who reported high values in health-related and health habit-related questions during the first year of studies had graduated more often during the 6-year follow-up compared with those reporting low values (table 2). Of the students who reported high enthusiasm and high engagement in studies during the first year of studies, more than $80 \%$ had graduated, while among students reporting low values, fewer than half had graduated.

In the multivariable logistic regression model, the study fields of (1) medicine and (2) natural sciences, agriculture and forestry, and pharmacy were positively associated with non-graduation in both sexes (figure 2A). The predictors in the eHQ associated with non-graduation differed among women and men. Among the female students, low enthusiasm about studies (OR 2.6, 95\% CI 1.9 to 3.6), low engagement with studies (OR 2.5, 95\% CI 1.8 to 3.4 ) and daily smoking (OR $1.9,95 \%$ CI 1.4 to 2.6 ) were the strongest predictors of non-graduation. Among the male students, the predictors with the highest ORs for non-graduation were low engagement with studies (OR $3.7,95 \%$ CI 2.5 to 5.5 ) and class II or III obesity (BMI $\geq 35$ ) (OR 4.0, 95\% CI 1.9 to 8.8) (figure 2B).

Not attending the health check when referred was associated with non-graduation in both sexes (figure 2C). ORs for not graduating were 1.6 (95\% CI 1.3 to 1.9 ) in women and 1.3 (95\% CI 1.0 to 1.6 ) in men, respectively. The reference groups were the students who were considered not to have risk factors for study ability in the eHQ and had thus received electronic feedback supporting a healthy lifestyle. Attending the health check was not significantly associated with non-graduation in either sex.

Unadjusted and adjusted ORs for all predictors in the logistic regression models are presented in online supplemental file 2.

\section{DISCUSSION}

University entrants' low engagement and low enthusiasm about studies were the strongest predictors to nongraduation during the 6-year follow-up of this study. Of 
Table 2 eHQ responses $(n=7845)$ of the University entrants for the 2011-2012 academic year by graduation (graduated and not graduated) and by sex

eHQ respor

Enthusiasm about the field of study on a -10 to +10 scale

\begin{tabular}{|crrrrrr}
\hline High 8-10 & 3057 & 84 & 16 & 1472 & 75 & 25 \\
\hline Medium 0-7 & 1788 & 70 & 30 & 1113 & 61 & 39 \\
\hline Low -10--1 & 291 & 47 & 53 & 124 & 33 & 67 \\
\hline Engagement with studies on a -10 to +10 scale & & & & & \\
$\quad$ High 8-10 & 1984 & 86 & 15 & 906 & 78 & 22 \\
\hline Medium 0-7 & 2790 & 74 & 26 & 1570 & 67 & 33 \\
\hline Low -10--1 & 362 & 51 & 49 & 233 & 34 & 67 \\
\hline
\end{tabular}

Health habits

\begin{tabular}{|c|c|c|c|c|c|c|}
\hline \multicolumn{7}{|l|}{ Exercise } \\
\hline Yes & 4450 & 78 & 22 & 2241 & 70 & 30 \\
\hline No & 686 & 70 & 31 & 468 & 58 & 42 \\
\hline \multicolumn{7}{|l|}{ Alcohol use } \\
\hline Do not use & 1046 & 75 & 25 & 490 & 67 & 33 \\
\hline AUDIT 1-7 points & 3036 & 78 & 22 & 1160 & 68 & 32 \\
\hline AUDIT 8-15 points & 940 & 75 & 25 & 932 & 68 & 32 \\
\hline AUDIT 16-19 points & 73 & 80 & 21 & 78 & 67 & 33 \\
\hline AUDIT $\geq 20$ points & 41 & 61 & 39 & 49 & 59 & 41 \\
\hline \multicolumn{7}{|l|}{ Used/tried drugs } \\
\hline No & 4687 & 78 & 23 & 2340 & 69 & 31 \\
\hline Yes & 449 & 71 & 29 & 369 & 59 & 42 \\
\hline \multicolumn{7}{|c|}{ Smoking or use of other tobacco products } \\
\hline No & 4216 & 78 & 22 & 1985 & 69 & 32 \\
\hline Occasionally & 701 & 74 & 26 & 472 & 68 & 32 \\
\hline Daily & 219 & 64 & 37 & 252 & 60 & 41 \\
\hline \multicolumn{7}{|c|}{ Healthiness of eating habits on $a-10$ to +10 scale } \\
\hline High 8-10 & 1401 & 79 & 21 & 543 & 73 & 27 \\
\hline Medium 0-7 & 3272 & 77 & 23 & 1854 & 67 & 33 \\
\hline Low -10--1 & 463 & 67 & 33 & 312 & 60 & 40 \\
\hline \multicolumn{7}{|c|}{ Adequacy and quality of sleeping on a -10 to +10 scale } \\
\hline High 8-10 & 1629 & 81 & 19 & 699 & 70 & 30 \\
\hline Medium 0-7 & 2623 & 77 & 23 & 1475 & 70 & 30 \\
\hline Low -10 to -1 & 884 & 68 & 32 & 535 & 58 & 42 \\
\hline \multicolumn{7}{|c|}{ Leisure time in terms of recovery, recreation and relaxation on a -10 to +10 scale } \\
\hline High 8-10 & 2763 & 79 & 21 & 1250 & 69 & 31 \\
\hline Medium 0-7 & 2152 & 75 & 25 & 1347 & 68 & 33 \\
\hline Low -10 to -1 & 221 & 68 & 32 & 112 & 56 & 44 \\
\hline \multicolumn{7}{|l|}{ General health } \\
\hline \multicolumn{7}{|c|}{ Reported chronic diseases } \\
\hline No & 4090 & 77 & 23 & 2221 & 69 & 31 \\
\hline Yes & 1046 & 75 & 25 & 488 & 62 & 38 \\
\hline
\end{tabular}

Continued 
Table 2 Continued

\section{eHQ responses}

\begin{tabular}{|c|c|c|c|c|c|}
\hline \multicolumn{3}{|c|}{ Female } & \multicolumn{3}{|l|}{ Male } \\
\hline Total & Graduated & Not graduated & Total & Graduated & Not graduated \\
\hline $\mathbf{n}$ & $\%$ & $\%$ & $n$ & $\%$ & $\%$ \\
\hline
\end{tabular}

Reported persistent or recurrent symptoms

$\begin{array}{lrrrrrr}\text { No } & 3286 & 78 & 22 & 1990 & 69 & 31 \\ \text { Yes } & 1850 & 75 & 25 & 719 & 65 & 35\end{array}$

General health status on $\mathrm{a}-10$ to +10 scale

\begin{tabular}{|c|c|c|c|c|c|c|}
\hline High 8-10 & 2601 & 81 & 19 & 1386 & 71 & 29 \\
\hline Medium 0-7 & 2223 & 74 & 26 & 1170 & 65 & 35 \\
\hline Low -10 to -1 & 312 & 64 & 37 & 153 & 55 & 45 \\
\hline <18.5 (underweight) & 358 & 75 & 25 & 80 & 64 & 36 \\
\hline 18.5-24.99 (normal weight) & 3944 & 78 & 22 & 1858 & 69 & 31 \\
\hline 30.0-34.99 (obese, class I) & 158 & 68 & 32 & 91 & 58 & 42 \\
\hline Z35 (obese, class II and III) & 49 & 69 & 31 & 32 & 38 & 63 \\
\hline
\end{tabular}

Dental health

\section{Latest dental check-up}

$\begin{array}{lrrrrrr}0-2 \text { years ago } & 3397 & 77 & 23 & 1716 & 67 & 33 \\ 3-5 \text { years ago } & 1518 & 77 & 24 & 804 & 68 & 32 \\ \text { More than 5 years ago } & 221 & 72 & 28 & 189 & 66 & 34\end{array}$

Eating and drinking times per day

$\begin{array}{lrrrrrr}6 \text { or less } & 4281 & 78 & 23 & 1983 & 68 & 32 \\ 7-10 & 814 & 74 & 26 & 659 & 68 & 32 \\ \text { More than } 10 & 41 & 71 & 29 & 67 & 66 & 34\end{array}$

Teeth brushing

Twice a day or more often

$\begin{array}{rrrrrr}4145 & 78 & 22 & 1607 & 70 & 30 \\ 964 & 73 & 28 & 1027 & 65 & 35 \\ 27 & 78 & 22 & 75 & 43 & 57\end{array}$

Less than once a day

$27-78$

22

57

Cavities that require filling at dental check-ups

\begin{tabular}{|ccccccc} 
Never & 1344 & 77 & 23 & 769 & 70 & 30 \\
\hline Seldom & 2529 & 77 & 23 & 1403 & 68 & 32 \\
$\quad$ Often or every time & 1263 & 76 & 24 & 537 & 64 & 36 \\
Dental fear & & & & & \\
\hline Not at all & 2869 & 76 & 24 & 1985 & 68 & 32 \\
\hline Some & 1917 & 78 & 22 & 663 & 67 & 33 \\
Very much & 350 & 73 & 27 & 61 & 62 & 38 \\
\hline
\end{tabular}

Mental well-being and social relations

Normal attitude towards food

\begin{tabular}{lrrrrrr} 
Yes & 4149 & 78 & 22 & 2526 & 68 & 32 \\
No & 254 & 64 & 36 & 31 & 55 & 45 \\
Can't say & 733 & 73 & 27 & 152 & 59 & 41 \\
Usual state of mind on a -10 to +10 scale & & & & \\
High 8-10 & 2134 & 81 & 19 & 1034 & 73 & 27 \\
Medium 0-7 & 2656 & 76 & 24 & 1510 & 66 & 34 \\
Low -10 to -1 & 346 & 60 & 40 & 165 & 53 & 47 \\
\hline
\end{tabular}

Continued 
Table 2 Continued

eHQ responses

\begin{tabular}{lllllll} 
Female & & & & & & \\
Total & Graduated & Not graduated & & Total & Graduated & Not graduated \\
\hline $\mathbf{n}$ & $\%$ & $\%$ & $\mathrm{n}$ & $\%$ & $\%$
\end{tabular}

Experience of loneliness on $\mathrm{a}-10$ to +10 scale

$\begin{array}{lrrrrrr}\text { High 8-10 } & 2548 & 79 & 21 & 1176 & 72 & 28 \\ \text { Medium 0-7 } & 1904 & 76 & 24 & 1117 & 65 & 35 \\ \text { Low -10 to }-1 & 684 & 71 & 29 & 416 & 61 & 39\end{array}$

Relationship with the parents on a scale -10 to +10

$\begin{array}{lrllllll}\text { High 8-10 } & 3318 & 79 & 21 & 1718 & 71 & 29 \\ \text { Medium 0-7 } & 1577 & 73 & 27 & 917 & 62 & 38 \\ \text { Low }-10 \text { to }-1 & 241 & 72 & 28 & 74 & 66 & 34\end{array}$

Experiencing various social situations (eg, giving presentation) on a -10 to +10 scale

$\begin{array}{lrllrll}\text { High 8-10 } & 1453 & 80 & 20 & 761 & 68 & 32 \\ \text { Medium 0-7 } & 2537 & 79 & 21 & 1453 & 70 & 30 \\ \text { Low -10 to }-1 & 1146 & 69 & 32 & 495 & 61 & 39\end{array}$

Other issues

Presents willingness to discuss about sexual health

\begin{tabular}{lcccccc} 
No & 4380 & 77 & 23 & 2599 & 68 & 32 \\
Yes & 756 & 74 & 26 & 110 & 68 & 32 \\
\hline Presents willingness to discuss about & n non-specific matter & & & & \\
No & 4102 & 78 & 22 & 2314 & 68 & 32 \\
Yes & 1034 & 74 & 26 & 395 & 65 & 35 \\
\hline
\end{tabular}

The proportions were calculated from the respective sex-based line total. The differences between the graduates and non-graduates by sex were tested with the $\chi^{2}$ test, and only the significant $(p<0.01)$ results are shown.

AUDIT, Alcohol Use Disorders Identification Test; eHQ, Electronic Health Questionnaire.
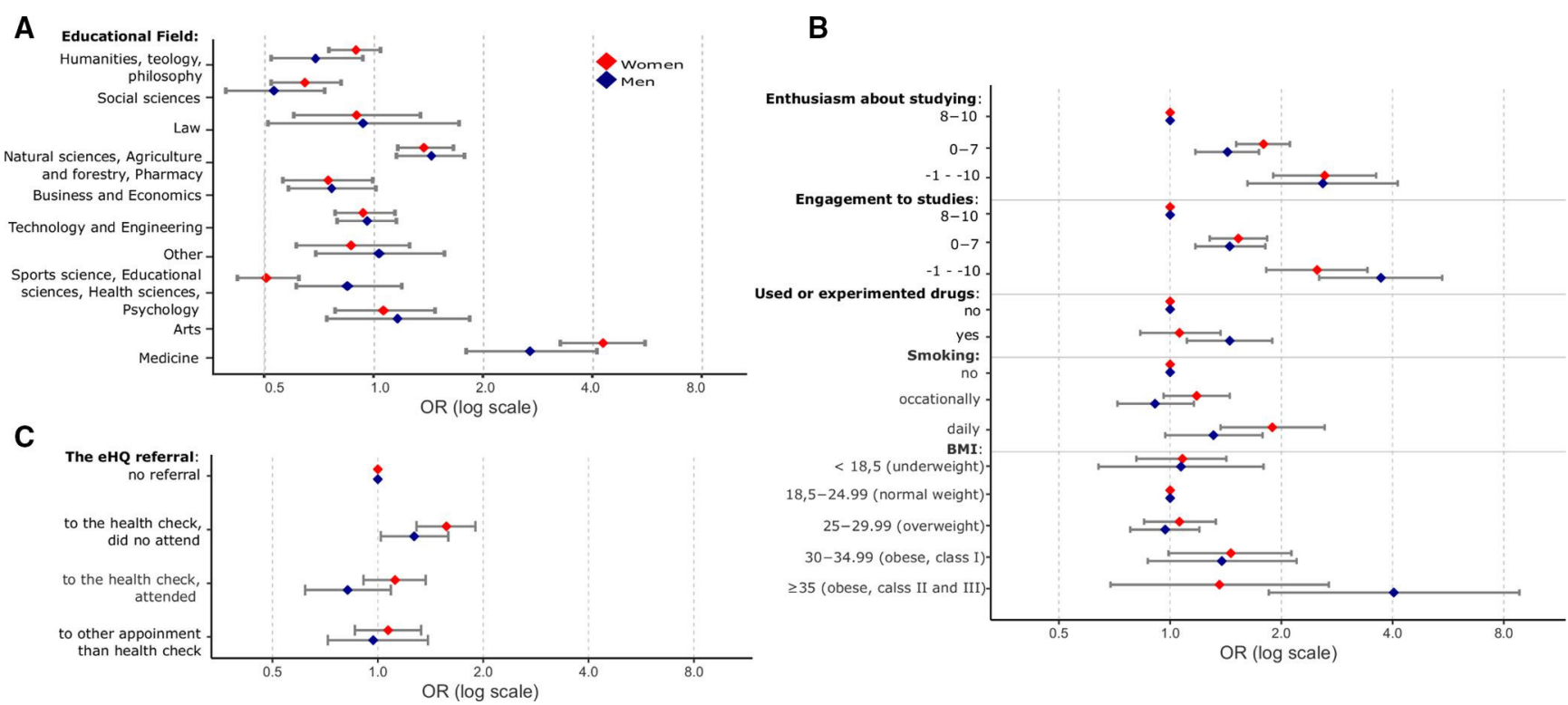

Figure 2 (A-C) OR plot with 95\% Cls for associations between (A) the field of study, (B) eHQ responses, (C) the health examination process and non-graduation. The red plots indicate women and blue plots indicate men. The reference of the OR for field of study is the mean of all study fields. BMI, body mass index; eHQ, Electronic Health Questionnaire. 
the health-related predictors, daily smoking in women and class II or III obesity (BMI $\geq 35$ ) and drug use in men were associated with non-graduation. By contrast, there was no association with mental well-being in either sex. Students who participated in the FSHS health examination process graduated more often than students who did not.

To our knowledge, this was the first study on factors associated with university students' graduation using such a wide selection of factors and a 6-year follow-up. For medical students, it seems the follow-up should have been longer since the curriculum is designed to take about six academic years. Medical students represent $3.5 \%$ of the study population; therefore, it is unlikely that the overall results were affected by this.

The major strengths of the study were the nationwide register data with good coverage and the high percentage of completed eHQs. The register data enabled the assessment of the national cohort of university entrants. The results may not be generalisable to university student populations in other countries due to different educational and healthcare systems.

The chosen outcome variable, graduation, is one of the clear strengths of the study. Gaining a degree is the main target of university education, and the registers are reliable on this achievement. In most previous studies, academic achievement has been measured by grade point average (GPA) or the students' self-estimate of their performance. ${ }^{17041}$ In publicly funded universities, such as those in Finland, the importance of graduation is emphasised based on the effective use of public resources.

It is a strength that the study used data gathered in real life, in the relevant healthcare setting. This enables the immediate practical implementation of the results. Using real-life data also has limitations. The eHQ was developed for practical purposes and was validated accordingly and not to the degree of scientific rigour. The response rate to the eHQ was $55 \%$, which is higher than that in national surveys conducted in the 20th century in the Finnish university student population. ${ }^{33}$ Repeated reminders, a common practice in research settings using surveys, could have improved the response rate. Furthermore, the way the nurses interpreted the eHQ responses relied on their professional competence, and for example, specific cut-offs were available for only some of the questions. ${ }^{24}$ The process as such had been in place for 2 years in 2011 and the professionals were routinely involved.

The eHQ data have the limitations of self-reported data and are therefore susceptible to bias. ${ }^{42}$ The somewhat complex response scale $(-10$ to +10$)$ might have resulted in varying interpretations by the respondents. ${ }^{43}$ The medical records of FSHS and the higher education achievement register are handled by humans and can therefore include errors. However, especially the higher education achievement register, in particular, is a reliable source of data on graduations, since this is also linked to the financing of the universities.
There is scarce evidence that is directly relevant to the findings of this study about the association between participating in the health examination process and graduation. We found that students who did not participate in the process at all, that is, the eHQ non-respondents, were the least likely to graduate in the 6-year follow-up. A previous study conducted on the same cohort as this study found that the non-respondents are healthier and have better health habits than the respondents. ${ }^{44}$ Therefore, we may speculate that the reasons explaining their lower graduation rate are not health related. In the present study, the students reporting risk factors for study ability in the eHQ were referred to a health check: the non-attendees had significantly higher odds of not graduating in the 6 years. The students who only received electronic feedback and those who attended their designated health check similarly achieved graduation. This suggests that providing proactive feedback and psychoeducation for students at entry and conducting health checks to students indicating health risk factors may be helpful to academic performance.

It has been suggested that student healthcare questionnaires should include questions about studying. ${ }^{45}$ The two study-related questions in the eHQ were both associated with graduation. The findings suggest that engagement and enthusiasm about studying in the first year are important predictors of graduation. It might be the case that students who felt they were in the wrong field of study or did not feel connected to the study community expressed low enthusiasm and low engagement. Detecting these problems early seems an important and potential intervention target. Introducing evidence-based intervention models as a collaboration of student healthcare and universities could be an effective method to address these problems. ${ }^{46-49}$

We found that daily smoking in women and repeated drug use in men were associated with non-graduation. These findings are in line with previous research. ${ }^{29} 5051$ Smoking and drug use may reflect poorer general life control or the lower socioeconomic status of the respondents, which could both have affected academic performance. ${ }^{52} 53$

This study supports the findings of He et al, who reported in their meta-analysis about a weak negative correlation between BMI and academic achievement. ${ }^{21}$ They did not find any difference between the sexes, whereas in this study, the association between high BMI and nongraduation was found only in men. BMI in this study was self-reported. It is possible that weight was under-reported especially, in case of overweight women. ${ }^{54}{ }^{55}$ The underlying mechanisms of this association remains unclear.

It was quite surprising that none of the questions about mental well-being and social relations were associated with non-graduation in the final models, even though the questions were associated in univariate models. The study of Vaez and Laflamme was performed in a quite similar setting in Sweden, and the outcome variable was also the similar: 'completion of a degree'. ${ }^{10}$ They neither found 
an association between several psychological factors measured and academic achievement. Further, Topham and Moller did not find links between psychological wellbeing of students entering the university and academic achievement in the end of the first year. ${ }^{56}$

On the contrary, Bruffaerts et al reported that freshmen with mental health problems have significantly lower academic functioning during the first year than other students. ${ }^{12}$ Depression has been found to be associated with a decrease, and anxiety with an increase in GPA. ${ }^{15} 41$ Grøtan et al reported a strong association between symptoms of mental distress, academic self-efficacy and study progress. ${ }^{57}$ In these studies, academic achievement was measures by short-term measures like GPA, whereas the present study and that of Vaez et al used a long-term outcome, graduation. The possibility of mental health issues having short-term effects without having long-term effects in academic achievement should be considered. This might be due to symptoms passing over time or as a result of treatment. It is also possible that the FSHS health examination process enhanced the detection and treatment of mental health issues, and therefore, no association with graduation was detected. In order to get a deeper insight, FSHS should in the future consider, including validated measures of mental health in the eHQ.

Student healthcare is primarily a preventive healthcare service. However, the need for medical service provision, especially in mental health issues, is currently considered critical and may therefore be prioritised over preventive measures. Motivating university entrants to improve their health habits may, in addition to health benefits, have a positive effect on academic achievement. Conducting health checks on a screened student population might be one effective way to do this. The findings of this study can be used to support and motivate the student healthcare personnel and management, as well as universities to invest more in preventive work.

\section{Twitter Noora Seilo @noora_seilo}

Acknowledgements We want to thank Finnish Student Health Service for enabling this study.

Contributors NS designed the study. NS and SP collected the data. NS processed the data and wrote the manuscript. SP, KK and MK significantly contributed to the design of the study and revised the manuscript. RA significantly contributed to the statistical design and revised the manuscript. All authors have read and approved the final manuscript.

Funding This work was supported by the Social Insurance Institution of Finland grant number Dnro 29/26/2017 and City of Tampere (Tiederahasto). The funders did not have any role in the study design, data collection, management, analyses, interpretation of data or writing of this manuscript.

Competing interests NS reports grants from the Social Insurance Institution of Finland during the conduct of the study. SP reports grants from Social Insurance Institution of Finland during the conduct of the study.

\section{Patient consent for publication Not required.}

Ethics approval The study is being conducted under the guidelines of the Finnish National Board on Research Integrity. The study has been ethically reviewed by the ethics committee of the Tampere Region (review 2/2017). The review was affirmative. The study has been evaluated and authorised by the Finnish National Institute of Health and Welfare, which authorises the research use of confidential data in Finland (Dnro THL/1364/5.05.00/2017). The study has received permission from the Finnish Student Health Service to conduct research. All 13 Finnish universities have given permission for their part to use the Higher education achievement register. The participants were not asked to give an informed consent due to the high number of participants. A risk assessment and data protection plan has been delivered to the Finnish office of the data protection ombudsman.

Provenance and peer review Not commissioned; externally peer reviewed.

Data availability statement Data may be obtained from a third party and are not publicly available. The data presented in the study is available from Finnish Student Health Service and The Finnish Ministry of Education and Culture; however, restrictions apply to the availability of these data. In this study, the data were used under the licence conceded by Finnish institute for health and Welfare (Dnro THL/1364/5.05.00/2017), which forbids data sharing and therefore the data are not publicly available.

Supplemental material This content has been supplied by the author(s). It has not been vetted by BMJ Publishing Group Limited (BMJ) and may not have been peer-reviewed. Any opinions or recommendations discussed are solely those of the author(s) and are not endorsed by BMJ. BMJ disclaims all liability and responsibility arising from any reliance placed on the content. Where the content includes any translated material, BMJ does not warrant the accuracy and reliability of the translations (including but not limited to local regulations, clinical guidelines, terminology, drug names and drug dosages), and is not responsible for any error and/or omissions arising from translation and adaptation or otherwise.

Open access This is an open access article distributed in accordance with the Creative Commons Attribution Non Commercial (CC BY-NC 4.0) license, which permits others to distribute, remix, adapt, build upon this work non-commercially, and license their derivative works on different terms, provided the original work is properly cited, appropriate credit is given, any changes made indicated, and the use is non-commercial. See: http://creativecommons.org/licenses/by-nc/4.0/.

ORCID iDs

Noora Seilo http://orcid.org/0000-0003-4585-0167

Minna Kaila http://orcid.org/0000-0002-9645-4925

\section{REFERENCES}

1 El Ansari W, Stock C. Is the health and wellbeing of university students associated with their academic performance? Cross sectional findings from the United Kingdom. Int J Environ Res Public Health 2010;7:509-27.

2 Paldanius S, Seilo N, Kunttu K, et al. Screening university students for health checks with an electronic health questionnaire in Finland: protocol for a retrospective, register-based cohort study. JMIR Res Protoc 2020;9:e14535.

3 Kunttu K, Pesonen T, Saari J. Student health survey 2016: a national survey among Finnish university students, 2016. Available: https:// www.yths.fi/en/fshs/research-and-publications/the-finnish-studenthealth-survey-2/ [Accessed 3 Jun 2020].

4 Vaez M, Ponce de Leon A, Laflamme L. Health-related determinants of perceived quality of life: a comparison between first-year university students and their working Peers. Work 2006;26:167-77.

5 Stewart-Brown S, Evans J, Patterson J, et al. The health of students in Institutes of higher education: an important and neglected public health problem? J Public Health 2000;22:492-9.

6 Auerbach RP, Alonso J, Axinn WG, et al. Mental disorders among college students in the world Health organization world mental health surveys. Psychol Med 2016;46:2955-70.

7 Auerbach RP, Mortier P, Bruffaerts R, et al. WHO world mental health surveys international college student project: prevalence and distribution of mental disorders. J Abnorm Psychol 2018;127:623-38.

8 Storrie K, Ahern K, Tuckett A. A systematic review: students with mental health problems-A growing problem. Int $J$ Nurs Pract 2010;16:1-6.

9 Flueckiger L, Lieb R, Meyer $\mathrm{AH}$, et al. How health behaviors relate to academic performance via affect: an intensive longitudinal study. PLoS One 2014;9:e111080.

10 Vaez M, Laflamme L, stress E. Experienced stress, psychological symptoms, self-rated health and academic achievement: a longitudinal study of Swedish university students. Soc Behav Pers 2008;36:183-96.

11 SUNDQVIST UB. Academic performance and mental health, in university students. A two year follow-up study of a sample of first-year students at the University of Uppsala 1968. Acta Psychiatr Scand 1973;49:64. 
12 Bruffaerts R, Mortier P, Kiekens G, et al. Mental health problems in college freshmen: prevalence and academic functioning. J Affect Disord 2018;225:97-103.

13 Knapstad M, Sivertsen B, Knudsen AK, et al. Trends in self-reported psychological distress among college and university students from 2010 to 2018. Psychol Med 2019;152:1-9.

14 Boot CRL, Vonk P, Meijman FJ. Health-related profiles of study delay in university students in the Netherlands. Int J Adolesc Med Health 2007;19:413-23.

15 Duffy A, Keown-Stoneman C, Goodday S, et al. Predictors of mental health and academic outcomes in first-year university students: identifying prevention and early-intervention targets. BJPsych Open 2020;6:e46.

16 Abdulghani HM, Alrowais NA, Bin-Saad NS, et al. Sleep disorder among medical students: relationship to their academic performance. Med Teach 2012;34:S37-41.

17 Trockel MT, Barnes MD, Egget DL. Health-related variables and academic performance among first-year college students: implications for sleep and other behaviors. J Am Coll Heal 2000;49:125-31.

18 Gaultney JF. The prevalence of sleep disorders in college students: impact on academic performance. J Am Coll Health 2010;59:91-7.

19 Haile YG, Alemu SM, Habtewold TD. Insomnia and its temporal association with academic performance among university students: a cross-sectional study. Biomed Res Int 2017;2017:1-7.

20 Al-Drees A, Abdulghani H, Irshad M, et al. Physical activity and academic achievement among the medical students: a crosssectional study. Med Teach 2016;38(Suppl 1):S66-72.

$21 \mathrm{He} J$, Chen X, Fan X, et al. Is there a relationship between body mass index and academic achievement? A meta-analysis. Public Health 2019;167:111-24.

22 Health care act (1326/2010). Available: http://www.finlex.fi/en/laki/ kaannokset/2010/en20101326_20131293.pdf [Accessed 3 Jun 2020].

23 Government decree 338/2011 on maternity and child health clinic services, school and student health services and preventive oral health services for children and youth. Available: https://www.finlex. $\mathrm{fi} / \mathrm{fi} /$ laki/kaannokset/2011/en20110338.pdf [Accessed 3 Jun 2020].

24 Kunttu K, Huttunen T. Lyhyt terveyskysely tunnistaa uuden opiskelijan terveysriskit [summary in English]. Finnish Med J 2008;63:3216-22.

25 Minkkinen J, Lindfors P, Kinnunen J, et al. Health as a Predictor of Students' Academic Achievement: A 3-Level Longitudinal Study of Finnish Adolescents. J Sch Health 2017;87:902-10.

26 Rasberry CN, Tiu GF, Kann L, et al. Health-Related behaviors and academic achievement among high school students - United States, 2015. MMWR Morb Mortal Wkly Rep 2017;66:921-7.

27 Stea TH, Torstveit MK. Association of lifestyle habits and academic achievement in Norwegian adolescents: a cross-sectional study. BMC Public Health 2014;14:829.

28 Faught EL, Gleddie D, Storey KE, et al. Healthy lifestyle behaviours are positively and independently associated with academic achievement: an analysis of self-reported data from a nationally representative sample of Canadian early adolescents. PLoS One 2017;12:e0181938.

29 Busch V, Loyen A, Lodder M, et al. The effects of adolescent health-related behavior on academic performance. Rev Educ Res 2014;84:245-74.

30 von Elm E, Altman DG, Egger M, et al. The strengthening the reporting of observational studies in epidemiology (STROBE) statement: guidelines for reporting observational studies. J Clin Epidemiol 2008:61:344-9.

31 Reinert DF, Allen JP. The alcohol use disorders identification test: an update of research findings. Alcohol Clin Exp Res 2007;31:185-99.

32 Babor TF, Higgins-Biddle JC, Saunders JB, et al. The alcohol use disorders identification test guidelines for use in primary care. 2nd edn, 2001.

33 Hauschildt K, Vögtle EM, Gwosc C. EUROSTUDENT VI overview and selected findings. social and economic conditions of student life in Europe. Bielefeld 2018.

34 WHO. Obesity: preventing and managing the global epidemic. Report of a WHO consultation (WHO technical report series 894). Geneva, 2000. ISBN: 9241208945
35 Vipunen, education statistics Finland. Available: https://vipunen.fi/fifi/_layouts/15/xlviewer.aspx?id=/fi-fi/Raportit/Tutkinnon [Accessed 3 Jun 2020].

36 Digital and population data services agency - the personal identity code. Available: https://dvv.fi/en/personal-identity-code [Accessed 13 Oct 2020].

37 Gissler M, Haukka J. Finnish health and social welfare registers in epidemiological research. Nor Epidemiol 2004;14:113-20.

38 R Core Team. R: a language and environment for statistical computing, 2018. Available: https://www.r-project.org/ [Accessed 3 Jun 2020].

39 Wickham H. ggplot 2: elegant graphics for data analysis. New York: Springer-Verlag, 2016. ISBN: 978-3-319-24277-4.

40 Casuso-Holgado MJ, Cuesta-Vargas Al, Moreno-Morales N, et al. The association between academic engagement and achievement in health sciences students. BMC Med Educ 2013;13:33.

41 Hysenbegasi A, Hass SL, Rowland CR. The impact of depression on the academic productivity of university students. J Ment Health Policy Econ 2005;8:145-51.

42 Brener ND, Billy JOG, Grady WR. Assessment of factors affecting the validity of self-reported health-risk behavior among adolescents: evidence from the scientific literature. J Adolesc Health 2003;33:436-57

43 Austin EJ, Deary IJ, Gibson GJ, et al. Individual response spread in self-report scales: personality correlations and consequences. Pers Individ Dif 1998;24:421-38.

44 Ritakorpi M, Kaunonen M, Kaila M, et al. The non-response of university students to an electronic health questionnaire - nonresponse analysis. [Sähköiseen terveyskyselyyn vastaamatta jättäneet yliopisto-opiskelijat]. J Soc Med 2019;56.

45 Boot CRL, Donders NCGM, Vonk P, et al. Development of a student health questionnaire: the necessity of a symbiosis of science and practice. Glob Health Promot 2009;16:35-44.

46 Murray NG, Low BJ, Hollis C, et al. Coordinated school health programs and academic achievement: a systematic review of the literature. J Sch Health 2007;77:589-600.

47 Shaw SR, Gomes P, Polotskaia A, et al. The relationship between student health and academic performance: implications for school psychologists. Sch Psychol Int 2015;36:115-34.

48 Langford R, Bonell CP, Jones HE, et al. The who health promoting school framework for improving the health and well-being of students and their academic achievement. Cochrane Database Syst Rev 2014:CD008958.

49 Tsouros A, Dowding G, Thompson J, et al. World Health Organization regional office for Europe Copenhagen health promoting universities concept, experience and framework for action. ISBN: 92128541998

50 Pennanen M, Haukkala A, de Vries $\mathrm{H}$, et al. Longitudinal study of relations between school achievement and smoking behavior among secondary school students in Finland: results of the ESFA study. Subst Use Misuse 2011;46:569-79.

51 Bugbee BA, Beck KH, Fryer CS, et al. Substance use, academic performance, and academic engagement among high school seniors. J Sch Health 2019;89:145-56.

52 Hiscock R, Bauld L, Amos A, et al. Socioeconomic status and smoking: a review. Ann N Y Acad Sci 2012;1248:107-23.

53 Lemstra M, Bennett NR, Neudorf C, et al. A meta-analysis of marijuana and alcohol use by socio-economic status in adolescents aged 10-15 years. Can J Public Health 2008;99:172-7.

54 Larsen JK, Ouwens M, Engels RCME, et al. Validity of self-reported weight and height and predictors of weight bias in female college students. Appetite 2008;50:386-9.

55 Connor Gorber S, Tremblay M, Moher D, et al. A comparison of direct vs. self-report measures for assessing height, weight and body mass index: a systematic review. Obes Rev 2007;8:307-26.

56 Topham P, Moller N. New students' psychological well-being and its relation to first year academic performance in a UK university. Couns Psychother Res 2011;11:196-203.

57 Grøtan K, Sund ER, Bjerkeset O. Mental health, academic selfefficacy and study progress among college students - The SHoT study, Norway. Front Psychol 2019;10:45. 